\title{
Degradation of Vancomycin Hydrochloride by Electrooxidation
}

\section{Antunes $\mathrm{MH}^{1}$, Arsand $\mathrm{DR}^{1 *}$ and Colvara WA ${ }^{2}$}

${ }^{1}$ Department of Environmental Sciences, Southern Brazilian Federal Institute for Education, Science and Technology (IFSul), Pelotas, Brazil

${ }^{2}$ Federal University of Pelotas, Pelotas, Brazil

\begin{abstract}
Many pharmaceuticals are considered recalcitrant pollutants and represent a problem for human and animal health due to continuous contribution in the aquatic environment and the bacteria resistance development to antibiotics. Vancomycin is one of the most antibiotics administered in medicine, nevertheless, there is not much knowledge about the presence, fate and the effects of Vancomycin in the environment. The advanced oxidation techniques (AOTs) are shown as alternatives for the treatment of water and wastewater in order to degrade pollutants and contaminants. Therefore, this work is aimed to evaluate the Vancomycin degradation in an aqueous medium using electrooxidation (EO) technique and to optimize the reaction conditions. The experiments were conducted in a homemade electrochemical cell in acrylic with a working volume of $500 \mathrm{~cm}^{3}$; DSA electrodes - Dimensionally Stable Anodes $\left(70 \mathrm{TiO}_{2}-30 \mathrm{RuO}_{2}\right)$ were used (effective area of work $-41.25 \mathrm{~cm}^{2}$ ); $\mathrm{NaCl}$ P.A. was used as supporting electrolyte; $130 \mathrm{mg} \mathrm{L}^{-1}$ of Vancomycin was used in aqueous solution. The optimization was done using central composite design (CCD) totaling 18 experiments. The evaluated factors were: interelectrodes distance (ID), applied current and supporting electrolyte concentration. All experiments were conducted for 20 minutes with sampling at $0,1,2,3,4,5,10$ and 20 minutes. Vancomycin concentrations were determined by High Performance Liquid Cromatography with Diode-Array Detection (HPLC-DAD) (Mobile phase: phosphate buffer $0.05 \mathrm{~mol} \mathrm{~L}^{-1}, \mathrm{pH}$ 4.7: $\mathrm{MeOH}$ : ACN [80:15:5, v/v], Injection volume: $40 \mathrm{~L}$; $\mathrm{C} 18$ with flow rate of $1.0 \mathrm{~mL} \mathrm{~min}^{-1}, \lambda: 210 \mathrm{~nm}$. The results show that the electrooxidation is effective in Vancomycin degradation, showing as an alternative to degradation of this drug. The method used obtained $100 \%$ of degradation in 2 minutes of treatment in optimum conditions: $400 \mathrm{~mA}, 3 \mathrm{~cm}$ interelectrodes distance and $1,100 \mathrm{mg} \mathrm{L}^{-1} \mathrm{NaCl}$.
\end{abstract}

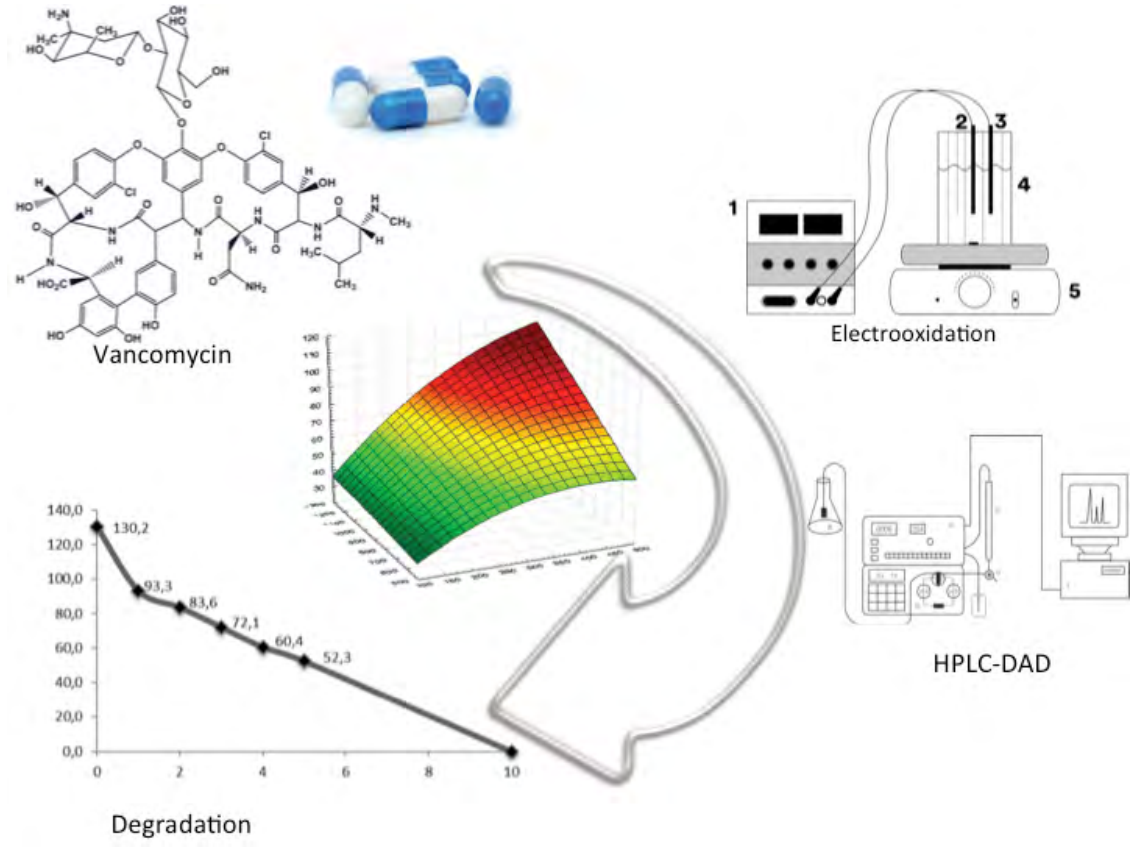

Keywords: Pharmaceutical drugs; Antibiotics; Electrochemical; Wastewater treatment

\section{Introduction}

In the 1970s, the scientific community initiated research on the presence of drugs in the environment and the possible impacts resulting from its perennial use, continuous intake and low concentrations [1]. Because of the presence of these substances and its byproducts in the environment, they are considered as a problem of great magnitude in many countries [2]. The introduction of drugs into the environment is mainly due to the disposal of urban sewage without being treated and due to human and animal excretion. However, soil fertilization with manure and effluents from the pharmaceutical industry cannot and
*Corresponding author: Daniel Ricardo Arsand, Teacher, Department of Environmental Sciences, Southern Brazilian Federal Institute for Education, Science and Technology (IFSul), Pelotas, Brazil, Tel: 5553984660120; E-mail: danielarsand@pelotas.ifsul.edu.br

Received August 11, 2017; Accepted August 19, 2017; Published August 23 , 2017

Citation: Antunes MH, Arsand DR, Colvara WA (2017) Degradation of Vancomycin Hydrochloride by Electrooxidation. Mod Chem Appl 5: 230. doi: 10.4172/23296798.1000230

Copyright: (c) 2017 Matheus HA, et al. This is an open-access article distributed under the terms of the Creative Commons Attribution License, which permits unrestricted use, distribution, and reproduction in any medium, provided the original author and source are credited. 
should not be disregarded. Antidepressants [3], anti-inflammatories [4], contraceptives [5] and antibiotics [6] are found in wastewater treatment plants (WWTPs), surface waters and groundwater with concentrations in the $\mathrm{ng}$ and $\mu \mathrm{g} \mathrm{L}^{-1}$ bands. Antibiotics occupy a prominent place among the classes of drugs spread in human and animal medicine. Kümmerer [7] considers antibiotics substances require special attention because they have different molecular structures along with diverse physical, chemical and biological characteristics and also because they behave in different ways with $\mathrm{pH}$ variation, such as: neutral, cationic, anionic or zwitterionic. Antibiotic resistance genes were found to many antibiotics, including Vancomym by Luprano [8] and Çardak [9]. Antibiotics are subdivided into several groups: Quinolones, $\beta$-Lactams, Tetracyclines, Macrolides and Glycopeptides. The class of glycopeptides has Vancomycin (Figure 1) as its main representative with high molecular mass, used in hospitals intravenously and mainly in infections caused by $S$. aureus and Enterococcus spp, where the microorganisms present some or total resistance to treatments or when the patient is allergic to penicillin. In addition, the microorganisms present resistance to Vancomycin itself, which is considered an antimicrobial (as a reference) in the treatment of such infections $[10,11]$. Searching for ways to contain the supply of antibiotics in the environment, numerous studies aim to develop and explore new types and/or new effluent treatment technologies, since the most widespread biological treatments achieve efficiencies of about $50 \%$ in the biodegradation of drugs in systems of activated sludge reactor; physical treatments only promote the transfer of drugs; and traditional chemical processes often do not promote complete mineralization of pharmaceuticals, ultimately by making available byproducts of them [1]. Qiu [12] studied Vancomycin under two typical pharmaceutical wastewater treatment plants and, despite the removal obtained, the results indicated the non-negligible environmental and health risks to Vancomycin. Advanced Oxidation Techniques (AOTs) have been shown as an efficient alternative in drug degradation. Lüddeke [13] have experimented with the efficiency of the ozonation process in various combinations with sand and charcoal filters in order to optimize the treatment totally for antibiotic resistant bacteria. The photo-peroxidation [14], Fenton [15] and Photo-fenton [16] are examples of AOTs used in water and effluent treatment. Following the line of the new treatment process, the electrooxidation has been used, also called as anodic oxidation when promotes the oxidation of molecules adsorbed on the surface of the inert electrode $[17,18]$. There is not much knowledge about the presence, fate and the effects of Vancomycin in the environment. This way, the objective of this work was to study the degradation of Vancomycin in an aqueous medium using electrooxidation technique and to optimize the process to promote the degradation of Vancomycin and its possible degradation products.

\section{Materials and Methods}

\section{Experimental optimization}

The experiments were optimized using experimental planning through the central composite design model (CCD), totaling 18 experiments: 8 factorial, 4 central and 6 axial. The three variable factors evaluated were: interelectrode distance $(2$ to $8 \mathrm{~cm}$ ), applied current (133 to $467 \mathrm{~mA}$ ), and the concentration of support electrolyte (566 to $\left.1234 \mathrm{mg} \mathrm{L}^{-1} \mathrm{NaCl}\right)$, together with 5 levels of significance $(-1.67,-1,0$, $+1 \mathrm{e}+1.67)$. Table 1 shows the evaluated factors and the matrix of the experiments. The analysis of variance (ANOVA) was used, considering

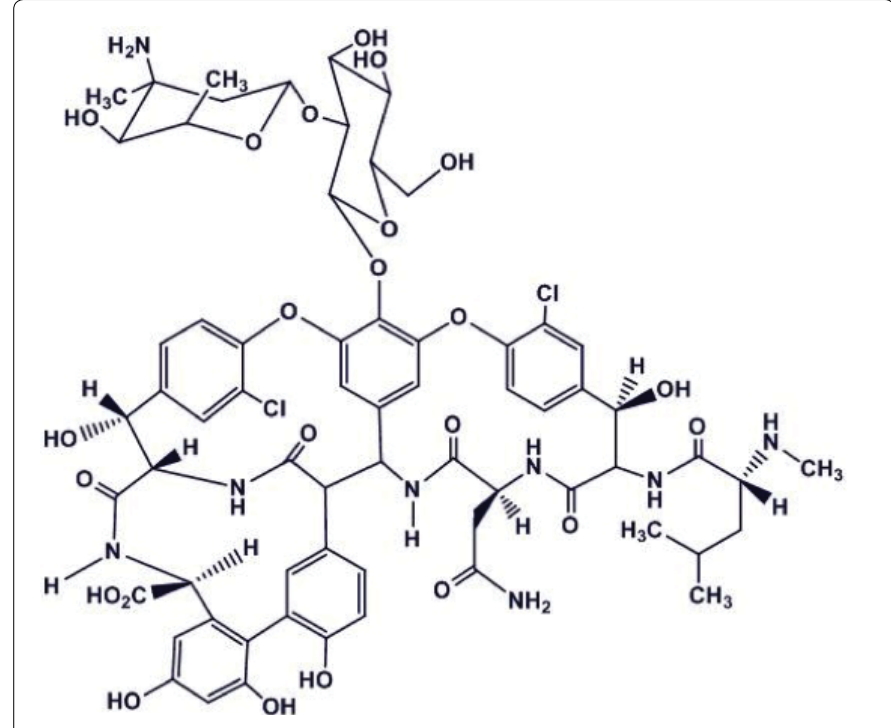

Figure 1: Molecular structure of Vancomycin.

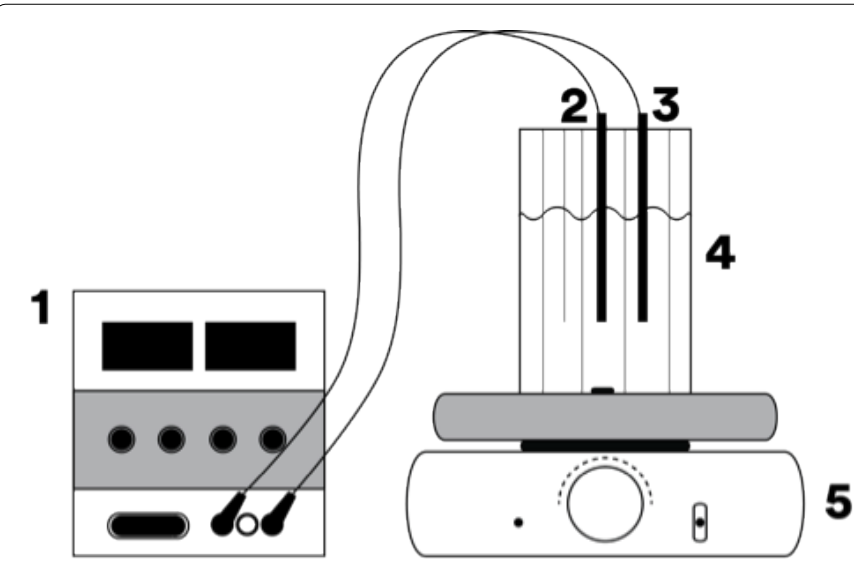

Figure 2: Electrochemical system for EO experiments: 1) current supply; 2) cathode DSA; 3 ) anode DSA; 4) electrochemical reactor; 5) magnetic stirrer.

the statistical significance of $95 \%(\mathrm{p}<0.05)$, to evaluate the significant parameters. The experiments were carried out at random to ensure the results would be reliable. (C) - Central point, control experiment.

\section{Analytical procedure}

Vancomycin concentrations were determined using a high performance liquid chromatograph with a diode arrangement detector (HPLC-DAD), a S3240 UV/VIS multi-channel detector and a S1125 pump system, both from Sykam, adapted according to Santos [19]. Mobile phase was composed of $0.05 \mathrm{~mol} \mathrm{~L}^{-1}$ phosphate buffer, $\mathrm{pH}$ 4.7:methanol:acetonitrile [80:15:5, v/v]. The injection volume was 40 $\mu \mathrm{L}$; a Dr. Maisch C18 reverse phase column $(250 \mathrm{~mm} \times 4.6 \mathrm{~mm}$ internal diameter) containing $5 \mu \mathrm{m}$ particles was used; the flow rate used was 1.0 $\mathrm{mL} \mathrm{min}^{-1}$, in a gradient elution system. Vancomycin was determined using the wavelength of $210 \mathrm{~nm}$ as reference. The analytical curve was constructed from five concentration points $(200,100,25$, and $12 \mathrm{mg}$ $\left.\mathrm{L}^{-1}\right)$ in triplicate $\left(\mathrm{y}=60.229+193.33 ; \mathrm{R}^{2}: 0.9982\right)$.

\section{Electrooxidation experiments}

The experiments were carried out in homemade electrochemical cells in acrylic with magnetic stirring; working volume of $500 \mathrm{~cm}^{3}$, 
Citation: Antunes MH, Arsand DR, Colvara WA (2017) Degradation of Vancomycin Hydrochloride by Electrooxidation. Mod Chem Appl 5: 230. doi: 10.4172/23296798.1000230

Page 3 of 5

\begin{tabular}{|c|c|c|c|}
\hline \multirow{2}{*}{ Experiment } & \multicolumn{3}{|c|}{ Factors (Real values) } \\
\hline & Current (mA) & Interelectrodes Distance (cm) & Support Electrolyte $\left(\mathrm{mg} \mathrm{L}^{-1}\right)$ \\
\hline 1 & $-1.00(200)$ & $-1.00(3)$ & $-1.00(700)$ \\
\hline 2 & $-1.00(200)$ & $1.00(7)$ & $1.00(1100)$ \\
\hline 3 & $1.00(400)$ & $-1.00(3)$ & $1.00(1100)$ \\
\hline 4 & $1.00(400)$ & $1.00(7)$ & $-1.00(700)$ \\
\hline $5(C)$ & $0.00(300)$ & $0.00(5)$ & $0.00(900)$ \\
\hline 6 & $-1.00(200)$ & $-1.00(3)$ & $1.00(1100)$ \\
\hline 7 & $-1.00(200)$ & $1.00(7)$ & $-1.00(700)$ \\
\hline 8 & $1.00(400)$ & $-1.00(3)$ & $-1.00(700)$ \\
\hline 9 & $1.00(400)$ & $1.00(7)$ & $1.00(1100)$ \\
\hline $10(\mathrm{C})$ & $0.00(300)$ & $0.00(5)$ & $0.00(900)$ \\
\hline 11 & $-1.67(133)$ & $0.00(5)$ & $0.00(900)$ \\
\hline 12 & $1.67(467)$ & $0.00(5)$ & $0.00(900)$ \\
\hline 13 & $0.00(300)$ & $-1.67(2)$ & $0.00(900)$ \\
\hline 14 & $0.00(300)$ & $1.67(8)$ & $0.00(900)$ \\
\hline 15 & $0.00(300)$ & $0.00(5)$ & $-1.67(566)$ \\
\hline 16 & $0.00(300)$ & $0.00(5)$ & $1.67(1234)$ \\
\hline $17(\mathrm{C})$ & $0.00(300)$ & $0.00(5)$ & $0.00(900)$ \\
\hline $18(\mathrm{C})$ & $0.00(300)$ & $0.00(5)$ & $0.00(900)$ \\
\hline
\end{tabular}

Table 1: Experiments and variable factors used in electrooxidation experiments.

\begin{tabular}{|c|c|c|c|}
\hline Experiment (n) & $1^{\text {st }}$ minute of degradation $(\%)$ & $2^{\text {nd }}$ minute of degradation (\%) & $3^{\text {rd }}$ minute of degradation (\%) \\
\hline 1 & 43.1 & 59.2 & 68.7 \\
\hline 2 & 39.2 & 63.3 & 79.0 \\
\hline 3 & 86.2 & 100.0 & 100.0 \\
\hline 4 & 39.0 & 73.3 & 100.0 \\
\hline 5 (c) & 40.2 & 78.5 & 79.9 \\
\hline 6 & 45.6 & 63.2 & 63.6 \\
\hline 7 & 31.4 & 48.3 & 58.0 \\
\hline 8 & 58.0 & 70.4 & 100.0 \\
\hline 9 & 56.4 & 86.9 & 91.4 \\
\hline $10(c)$ & 58.8 & 76.3 & 100.0 \\
\hline 11 & 28.4 & 35.8 & 44.6 \\
\hline 12 & 0.0 & 85.8 & 98.8 \\
\hline 13 & 51.4 & 70.3 & 83.0 \\
\hline 14 & 40.0 & 61.8 & 74.2 \\
\hline 15 & 30.3 & 55.5 & 70.0 \\
\hline 16 & 64.6 & 82.0 & 98.9 \\
\hline $17(\mathrm{c})$ & 49.4 & 70.6 & 92.3 \\
\hline 18 (c) & 51.0 & 69.5 & 86.9 \\
\hline
\end{tabular}

Table 2: Vancomycin degradation at the electrooxidation experiments.

\begin{tabular}{|c|c|c|c|c|}
\hline & Estimated & Standard error & T Value \\
\hline$X_{1}$ & 13.26430 & 1.641074 & 8.08269 \\
\hline$X_{2}$ & -3.29439 & 1.716838 & -1.91887 & 0.000011 \\
\hline$X_{3}$ & 7.84037 & 1.641074 & 4.77759 \\
\hline
\end{tabular}

Table 3: $T$ and $P$ values, standard error and estimated values for the parameters: applied current " $X_{1}$ ”; interelectrodes distance " $X_{2}$ ”; and concentration of support electrolyte "X".

DSA $^{\oplus}$ electrodes were used as anode and cathode (Figure 2) based on titanium oxide and ruthenium oxide in the ratio $\left(70 \mathrm{TiO}_{2}-30 \mathrm{RuO}_{2}\right)$ provided by De Nora (Brazil). The working current was applied using a Polimed ${ }^{\star}$ PMI 3002 S current source. Each electrode presented an effective working area of $41.25 \mathrm{~cm}^{2}$. The Vancomycin in all experiments was about $130 \mathrm{mg} \mathrm{L}-1$ in deionized water (prepared in the laboratory). $\mathrm{NaCl}$ P.A. was used as supporting electrolyte. The experiments lasted for 20 minutes and samples were collected at $0,1,2,3,4,5,10$ and 20 minutes and stored in the absence of light at $4 \pm 1^{\circ} \mathrm{C}$ until analytical procedures.

\section{Results and Discussion}

Vancomycin electrooxidation and optimization of the reaction parameters

The results obtained in the EO experiments of Vancomycin are presented in Table 2. It can be seen that at 3 minutes of electrooxidation, four experiments reached $100 \%$ of degradation of Vancomycin hydrochloride. However, this time is not adequate for optimization of parameters, as it does not allow evaluation of the best efficiency related to the reaction conditions. Therefore, the degradations obtained in 2 minutes for the optimization of the reaction conditions were evaluated. 


\section{Optimization of reactional conditions}

The mathematical model used to evaluate the influence of analyzed parameters on Vancomycin EO, considering the CCD model, is presented in Equation 1.

\section{$\mathrm{Y}=\mathrm{bo}+\mathrm{b} 1 . \mathrm{x} 1+\mathrm{b} 11 . \mathrm{x} 12+\mathrm{b} 3 \times \mathrm{x} 3+\mathrm{b} 33 . \mathrm{x} 32+\mathrm{b} 22 \cdot \mathrm{x} 22+\mathrm{b} 2 . \mathrm{x} 2+\mathrm{x} 1 . \mathrm{x} 2 . \mathrm{b} 123 \mathrm{Eq} .1$}

The analysis of variance (ANOVA) of the results obtained is presented in Table 3 , considering statistical significance of $95 \%(\mathrm{p}<0.05)$. The results showed that $90.44 \%\left(\mathrm{R}^{2}\right)$ of the degradation is explained by the proposed value. Thus, it can be observed that the concentration of support electrolyte used and the current applied are significant in the electrooxidation of Vancomycin, whereas the interelectrode distance, under the tested conditions, is not Martínez-Huitle [20] carried out the effluent electrooxidation of the textile industry by varying the applied current and obtained better results, even in shorter experiment times by applying higher electric currents. In the same sense, Singh [21] obtained better indices of dye degradation by applying higher currents using DSA electrodes. Malpass [22] obtained 100\% degradation as a result, after $1 \mathrm{~h}$ of electrooxidation by being efficient in a similar configuration (DSA electrodes and $\mathrm{NaCl}$ as support electrolyte), in the oxidation of pesticide atrazine.

The degradation of Vancomycin, under these conditions, resulted in the quadratic mathematical model (Equation 2):

\section{Eq. 2}

$$
\mathrm{D} \%=7.3611+0.177 \mathrm{x}+0.0009 \mathrm{y}-0.0003 \mathrm{x} 2+0.0002 \mathrm{xy}-3.947310-6 \mathrm{y} 2
$$

where, "D\%" is Vancomycin degradation [\%], " $\mathrm{x}$ " is applied current $[\mathrm{mA}]$ and " $\mathrm{y}$ " is support electrolyte concentration [mg L" $\mathrm{m}^{-1}$.

The response surface resulting from this process is shown in Figure 3 which allows the visualization of the behavior of response (degradation) in relation to the different values of the electrolyte and the applied electric current. The points marked on the surface represent Experiment 3 (I: $400 \mathrm{~mA}$ and $\mathrm{NaCl} 1100 \mathrm{mg} \mathrm{L}^{-1}$ ) as the best result whereas experiment 11 (I: $133 \mathrm{~mA}$ and $\mathrm{NaCl} 900 \mathrm{mg} \mathrm{L}^{-1}$ ) reached the lowest percentage of degradation. It can be seen that the degradation of Vancomycin is more pronounced in conditions where higher currents are applied and higher concentrations of support electrolyte

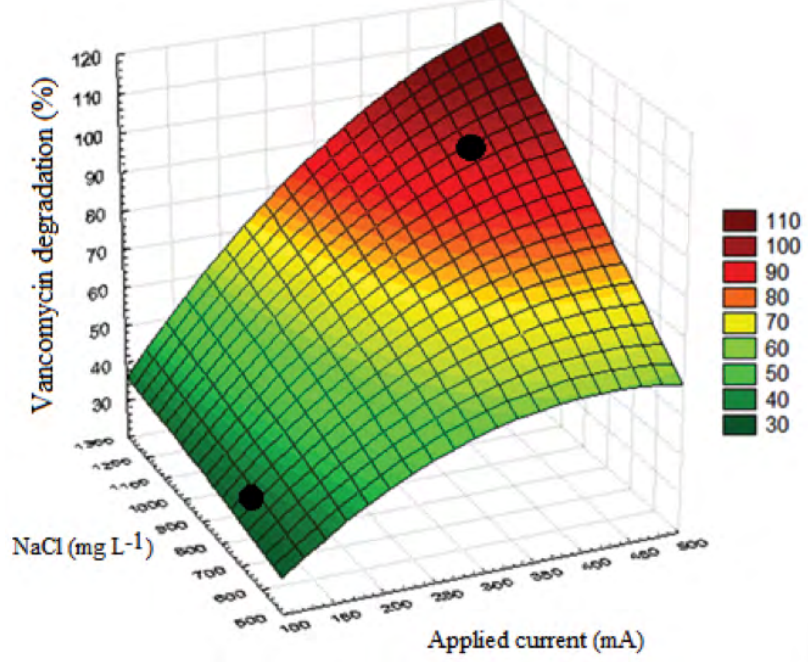

Figure 3: Response surface for degradation of Vancomycin hydrochloride in function of variation of electrolyte concentration and the applied electric current.

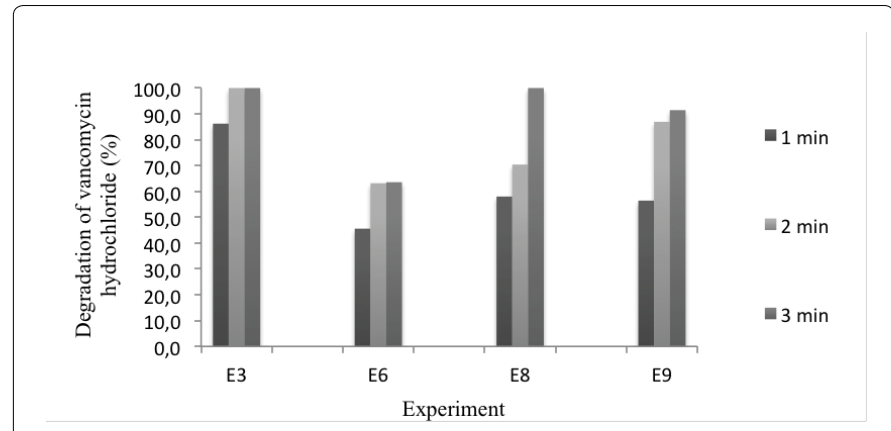

Figure 4: Comparative between oxidation times and the respective degradation of Vancomycin hydrochloride.

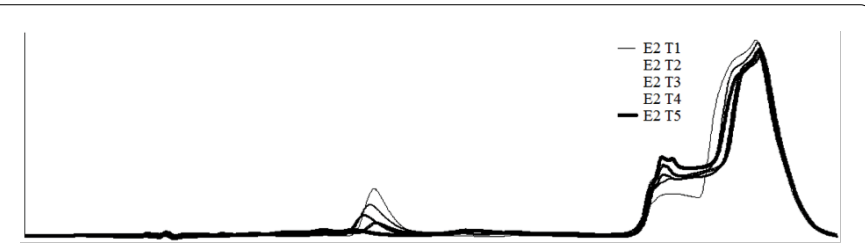

Figure 5: Chromatogram of experiment 2, samples between one to five minutes of oxidation.

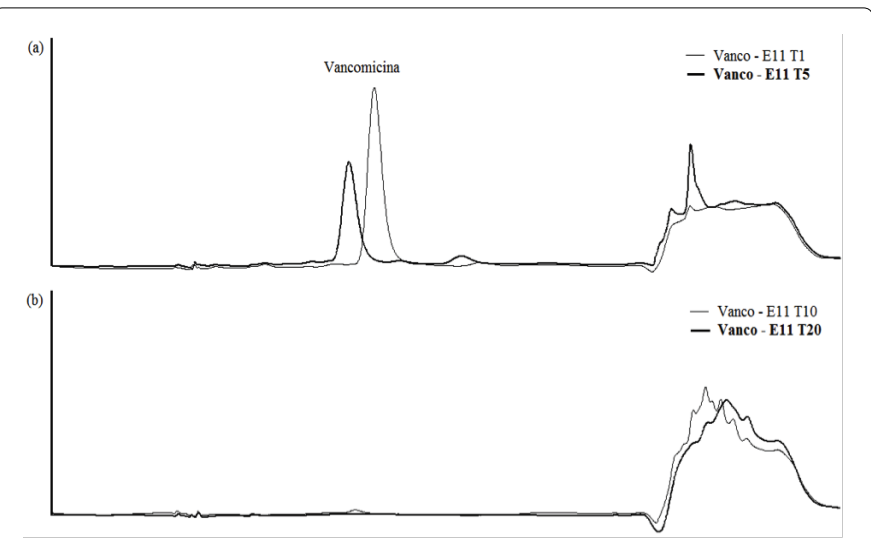

Figure 6: Chromatograms between 1 and 5 minutes of electrooxidation (a); 10 and 20 minutes of experiment 11 (b).

are used. This behavior is attributed to the sum of direct and indirect oxidation processes, since better results are obtained in the presence of chloride ions due to the indirect oxidation resulting from the formation of molecular chlorine in the medium [23] or even resulting from the formation of hydroxyl radicals (HO.) [21]. Thus, the higher Vancomycin degradation efficiency of experiment 3 is attributed to the promotion of molecular chlorine generation $\left(\mathrm{Cl}_{2}\right)$ due to the higher concentration of support electrolyte used.

\section{Evaluation of the resulting model and the results obtained}

The results obtained show the configuration of experiment 3 as a better degradation performance. Experiments 4, 8 and 10 also reached $100 \%$ degradation, however, with longer applied current. Comparing the reaction conditions, it is possible to see the use of higher electrolyte support in experiment 3 . These results confirm the mathematical model proposed and the response surface. Experiments 6, 8 and 9 (Figure 4) show the change of a single factor in relation to experiment 3 (I: 400 
Citation: Antunes MH, Arsand DR, Colvara WA (2017) Degradation of Vancomycin Hydrochloride by Electrooxidation. Mod Chem Appl 5: 230. doi: 10.4172/23296798.1000230

$\mathrm{mA}, 1100 \mathrm{mg} \mathrm{L}-1 \mathrm{NaCl}$ and ID: $3 \mathrm{~cm})$ : applied current $(200 \mathrm{~mA})$ in experiment 6; Concentration of the supporting electrolyte $(700 \mathrm{mg}$ L-1) in experiment 8 ; and interelectrode distance $(7 \mathrm{~cm})$ in experiment 9. Experiment 6 explains the dependence between the degradation of Vancomycin hydrochloride and the applied current; experiment 9 shows that the interelectrode distance also influences the performance of electrooxidation, however, with less interference in the oxidation; experiment 8 shows a lower electrolyte concentration and a condition in which $100 \%$ degradation is achieved.

\section{Degradation products and vancomycin mineralization}

Although Vancomycin is completely degraded in the first few minutes of the experiment, it can be seen as byproducts being generated from the mother molecule. Figures 5 and 6 shows the formation of other substance(s) during the course of experiment 2, which was chosen to allow better visualization of Vancomycin signal decay and increase of signals between 11 and 14 minutes of chromatographic reading. These experiments were done until 20 minutes to observe the byproducts formation/degradation.

\section{Conclusion}

The results showed that the EO technique was efficient in the degradation of Vancomycin hydrochloride (HVCM), under the conditions using $\mathrm{DSA}^{\infty}$ electrodes $\left(70 \mathrm{TiO}_{2}-30 \mathrm{RuO}_{2}\right)$. Furthermore, it can be stated that the best conditions for the degradation of Vancomycin in aqueous medium were $400 \mathrm{~mA}$ of applied current, 3 $\mathrm{cm}$ of interelectrode distance and $1100 \mathrm{mg} \mathrm{L}^{-1}$ of support electrolyte $[\mathrm{NaCl}]$. The electrical current is the main factor responsible for affecting the degradation of Vancomycin hydrochloride, but the use of sodium chloride as a support electrolyte and the generation of $\mathrm{Cl}_{2}$ during the oxidation process must be an attributed part of this degradation.

\section{Acknowledgements}

The authors gratefully acknowledge Capes Foundation (Brazilian Ministry of Education), Council for Scientific and Technological Development (CNPq) and the Federal Institute Sul-rio-grandense do Sul campus Pelotas for supporting the study.

\section{References}

1. Melo SAS, Trovó AG, Bautitz IR, Nogueira RFP (2009) Degradation of residual pharmaceuticals by advanced oxidation processes. Química Nova 32: 188-197.

2. Fatta K, Meric S, Nikolaou A (2011) Pharmaceutical Residues in Environmental Waters and Wastewaters: Current of Knowledge and Future Research. Analytical and Bioanalytical Chemistry 399: 251-275

3. Golovko O, Kumar V, Fedorova G, Randak T, Grabic R, et al. (2014) Seasonal changes in antibiotics, antidepressants/psychiatric drugs, antihistamines and lipid regulators in a wastewater treatment plant. Chemosphere 111: 418-426.

4. Brozinski JM, Lahti M, Meierjohann A, Oikari A (2012) The Anti-Inflammatory Drugs Diclofenac, Naproxen and Ibuprofen are found in the Bile of Wild Fish Caught Downstream of Wastewater Treatment Plant. Environmental Science \& Technology 47: 342-348.

5. Liu Z, Ogejo JA, Pruden A, Knowlton K (2011) Occurrence, fate and removal of synthetic oral contraceptives (SOCs) in the natural environment: A review. Science of The Total Environment 409: 5149-5161.

6. Frade VMF, Dias M, Teixeira ACSC, Palma MSA (2014) Environmental contamination by fluoroquinolones. Brazilian Journal of Pharmaceutical Sciences 50: 1-14

7. Kummerer K (2009) Antibiotics in the Aquatic Environment: A Review Part I. Chemosphere 75: 417-434.

8. Luprano ML, Sanctis M, Del MG, Di LC (2016) Antibiotic resistance genes fate and removal by a technological treatment solution for water reuse in agriculture. Science of the Total Environment 571: 809-818.

9. Qiu P, Guo X, Zhang Y, Chen X, Wang N, et al. (2016) Occurrence, fate, and risk assessment of vancomycin in two typical pharmaceutical wastewate treatment plants in Eastern China. Environmental Science and Pollution Research 23: 16513-16523.

10. Rincón S, Panesso D, Díaz L, Carvajal L, Reyes J, et al. (2014) Resistance to last-line antibiotics in Gram-positive cocci: the post-vancomycin era: The PostVancomycin era. Biomedical 34: 191-208.

11. Morris D, Galvin S, Boyle F, Hickey P, Mulligan M, et al. (2012) Enterococcus faecium of the van A Genotype in Rural Drinking Water, Effluent and the Aqueous Environment. Applied and Environmental Microbiology 78: 596-598.

12. Lüddeke F, Heß S, Gallert C, Winter J, Güde H, et al. (2015) Removal of Total and Antibiotic Resistant Bacteria in Advanced Wastewater Treatment by Ozonation in Combination with Different Filtering Techniques. Water Research 69: 243-251.

13. Keen O, Linden K (2013) Degradation of Antibiotic Activity during UV/ $\mathrm{H}_{2} \mathrm{O}_{2}$ Advanced Oxidation and Photolysis in Wastewater Effluent. Environmental Science \& Technology 47: 13020-13030.

14. Çardak M, Altug G, Ay M, Erol Ô (2016) Distribution of antibiotic resistance and the presence of vancomycin-resistance genes (vanA and vanB) in Enterobacteriaceae isolated from the Sea of Marmara, the Canakkale Strait and the Istanbul Strait, Turkey. Oceanological and Hydrobiological Studies: 45 182-190.

15. Babuponnusami A Muthukumar K (2014) A review on Fenton and improvements to the Fenton process for wastewater treatment. Journal of Environmental Chemical Engineering 2: 557-572.

16. Klamerth N, Malato S, Agüera A, Fernández A (2012) Treatment of Municipa Wastewater Treatment Plant Effluents with Modified Photo-Fenton as Tertiary Treatment for the Degradation of Micro Pollutants and Desinfection. Environmental Science \& Technology 46: 2885-2892.

17. Sirés I, Brillas E (2012) Remediation of Water Pollution Caused by Pharmaceutical Residues Based on Electrochemical Separation and Degradation Technologies: A Review. Environment International 40: 212-229.

18. Benito A, Penades A, Liberia JL, Gonzalez R (2016) Degradation pathways of aniline in aqueous solutions during electro-oxidation with BDD electrodes and $\mathrm{UV} / \mathrm{H}_{2} \mathrm{O}_{2}$ treatment. Chemosphere 166: 230-237.

19. Dos CR, Feferbaum R, De MLSA, Bertoline MA (2001) Micromethod for the quantification of vancomycin in plasma through high performance liquid chromatography: Plasma vancomycin monitoring in the pharmacological support of neonates with sepsis. Brazilian Journal of Pharmaceutical Sciences 37: 1.

20. Martínez C, Dos EV, De DM, Panizza M (2012) Applicability of diamond electrode/anode to the electrochemical treatment of a real textile effluent Journal of Electroanalytical Chemistry 674: 103-107.

21. Singh S, Shanglien L, Srivastavab VC, Hiwarkar AD (2016) Comparative study of electrochemical oxidation for dye degradation: Parametric optimization and mechanism identification. Journal of Environmental Chemical Engineering 4 2911-2921.

22. Malpass GRP, Miwaa DW, Machadoa SAS, Olivib P, Motheo AJ (2016) Oxidation of the pesticide atrazine at DSA® electrodes. Journal of Hazardous Materials 137: 565-572.

23. Wu W, Huang ZH, Lim TT (2016) A comparative study on electrochemica oxidation of bisphenol a by boron-doped diamond anode and modified $\mathrm{SnO}_{2}$-Sb anodes: Influencing parameters and reaction pathways. Journal of Environmental Chemical Engineering 4: 2807-2815. 